\title{
Staplers for obstructed defecation syndrome
}

\author{
F. S. P. Regadas ${ }^{1,2} \cdot$ F. S. P. Regadas Filho $0^{1,2}$
}

Received: 3 December 2017 / Accepted: 13 December 2017 / Published online: 20 January 2018

c) Springer International Publishing AG, part of Springer Nature 2018

A stapled technique for treatment of rectal mucosal prolapse was initially proposed by Pescatori, who published the first cases in 1997 [1]. Following that, Longo developed the first specific stapler (PPH $33 \mathrm{~mm}$ ) for hemorrhoidopexy and popularized the technique worldwide. Additionally, using the same stapler, he developed another technique, stapled transanal rectal resection (STARR), to treat obstructed defecation syndrome (ODS) associated with rectocele or intussusception. With the PPH stapler, only a limited amount of tissue can be removed, the cartridge cannot be detached and the shaft inside the cartridge is covered by a tube. This makes it difficult for the surgeon to assess what is incorporated in the stapler, remove a large sleeve of rectum and remove a symmetric amount of tissue. With the development of new and more dedicated staplers like HEM EEA-33 (Covidien), TST STARR PLUS (Touchstone) and Transtar (Ethicon), it is currently possible for the surgeon to achieve all these technical goals. In this issue of Techniques in Coloproctology, Naldini et al. [2] describe in great detail the technique and results of circumferential removal of the rectal wall using the TST STARR PLUS stapler in patients with rectocele and internal prolapse associated with ODS.

Besides the choice of the stapler and the surgical technique to be used, the most important factor determining satisfactory functional results is careful patient selection. This is achieved by evaluating all the patients with standardized questionnaires, physical examination and imaging. The dysfunctions of the posterior pelvic compartment are like an iceberg [3]: Rectocele is the first anatomical defect to appear but there are always others not readily seen, such as rectal

$\triangle$ F. S. P. Regadas Filho

sregadas@hotmail.com

F. S. P. Regadas

sregadas@hospitalsaocarlos.com.br

1 School of Medicine, Federal University of Ceara, Fortaleza, Brazil

2 Coloproctology Unit, Sao Carlos Hospital, Fortaleza, Ceará, Brazil intussusception or enterocele, or others such as anismus that can be found only after specific tests are performed. Based on this concept, it is mandatory to carry out a careful proctology examination and to confirm and quantify the physical findings with imaging tests such as cinedefecography, echodefecography (dynamic three-dimensional rectal ultrasound) and dynamic magnetic resonance imaging. It is also important to perform anal manometry to exclude anismus and evaluate sphincter function, and finally perform an urogynecologic evaluation before choosing the most appropriate surgical technique. Surgical treatment with a transanal stapled technique is indicated only if, after this comprehensive evaluation, the presence of rectocele, full mucosal prolapse and/or rectal intussusception is confirmed and anismus, enterocele, anterior or middle compartment prolapse, urge fecal incontinence or weak sphincters are excluded and only after the patient fails conservative treatment with fiber, laxatives and pelvic floor rehabilitation.

Which stapler and which technique? In patients with rectocele, the resection must be close to the dentate line (approximately $1.0 \mathrm{~cm}$ proximally) because the herniation starts at the anterior upper anal canal, as suggested by echodefecography [4], and consequently the herniation will persist if the stapled suture is positioned far above that level. Therefore, in female patients with rectocele associated with rectal intussusception, we have proposed the transanal repair of rectocele and rectal mucosectomy with one circular stapler (TRREMS) which may be performed with either the EEA-33 or TST STARR PLUS stapler [5]. These staplers make it possible to quantify the amount of tissue that must be removed and are associated with a low incidence of bleeding after firing which requires hemostatic suture (approximately $7 \%$ ). In contrast, the PPH stapler has a limited capacity and haemostatic suturing is required in about $20 \%$ of patients [6]. In the TREMMS technique, the rectocele is first removed manually using a continuous suture about $2.0 \mathrm{~cm}$ from the dentate line. Following that, a purse-string suture is placed to include both the intussusception and the rectocele sutures in order to remove a symmetric wedge of tissue (Fig. 1). This technique has been shown to be safe and effective in 


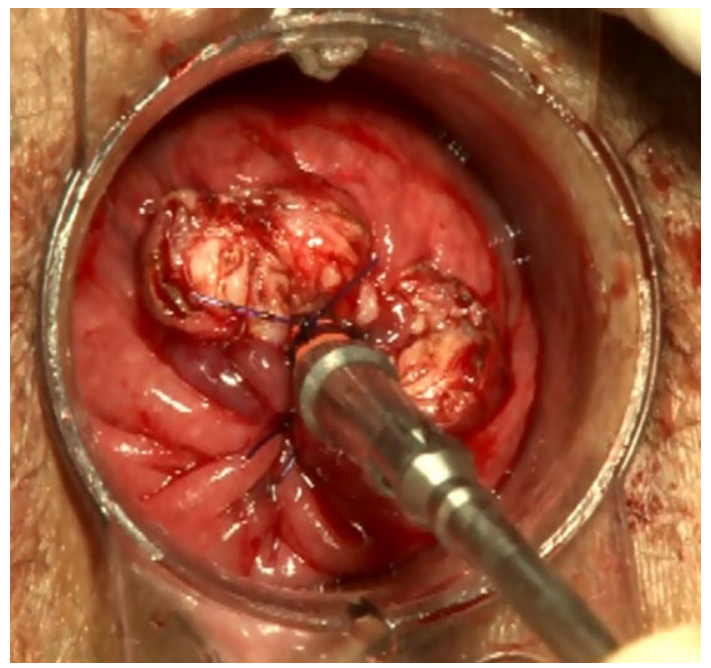

Fig. 1 TREMMS procedure: a suture is initially placed at the base of the rectocele, the rectocele is removed and the suture is incorporated in the purse-string

prospective studies in women with ODS and grade III rectocele, demonstrating a significant reduction of the Wexner constipation score from 16 to 4 and a $90 \%$ anatomical cure on defecography [5]. In order to avoid rectovaginal fistulas, it is recommended to pull up the posterior vagina wall using two Allis forceps during firing (Fig. 2).

Otherwise, in patients without rectocele and with rectal mucosal prolapse or intussusception, the apex technique [7] (using either the EEA-33 stapler or the TST STARR PLUS) or the technique proposed by Naldini et al. (using the TST STARR PLUS stapler) may be used. In the apex technique, the apex of the prolapse is identified and marked with four stitches, and then a purse-string suture is tied around the center rod of the EEA-33 stapler and passed through the most distal $(4 \mathrm{~cm})$ hole. Following this, a second pursestring suture $1.0 \mathrm{~cm}$ distal to the first is also tied around the center rod in order to remove more tissue and ensure a symmetric anastomosis (Fig. 3). Using this technique in 45 patients with rectal intussusception, the mean postoperative constipation score decreased from 13 to 5 and followup imaging demonstrated complete disappearance of rectal intussusception in all patients. Using the TST stapler, Naldini and colleagues quantified the amount of prolapsing tissue to be removed based on the amount found prolapsing into the circular anal dilator (CAD). In their experience, it was necessary to resect twice the length of the amount of tissue found in the CAD in order to free the CAD from the prolapse. The incorporation of tissue in the stapler was accomplished by placing six traction sutures pulled through the stapler's window at the time of firing as it is shown in their video [2]. In this fashion, they were able to eliminate both rectocele and internal prolapse. Although Naldini et al.

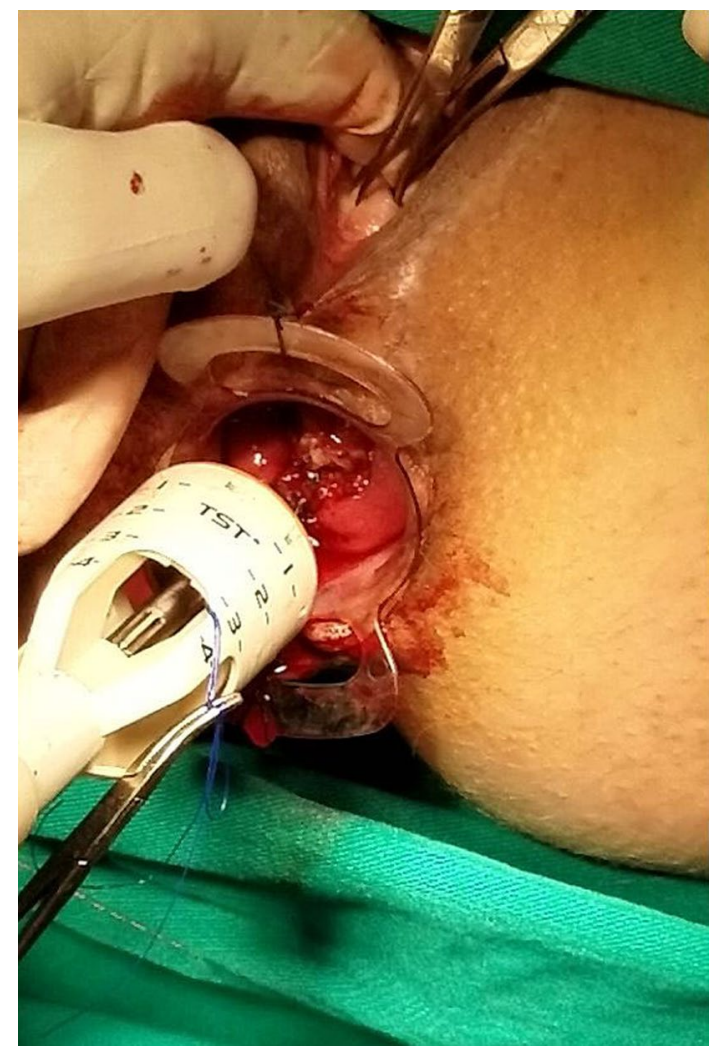

Fig. 2 It is very important to stay as far as possible from the vaginal wall. The authors routinely pull up the posterior vaginal wall with Allis forceps while firing the stapler

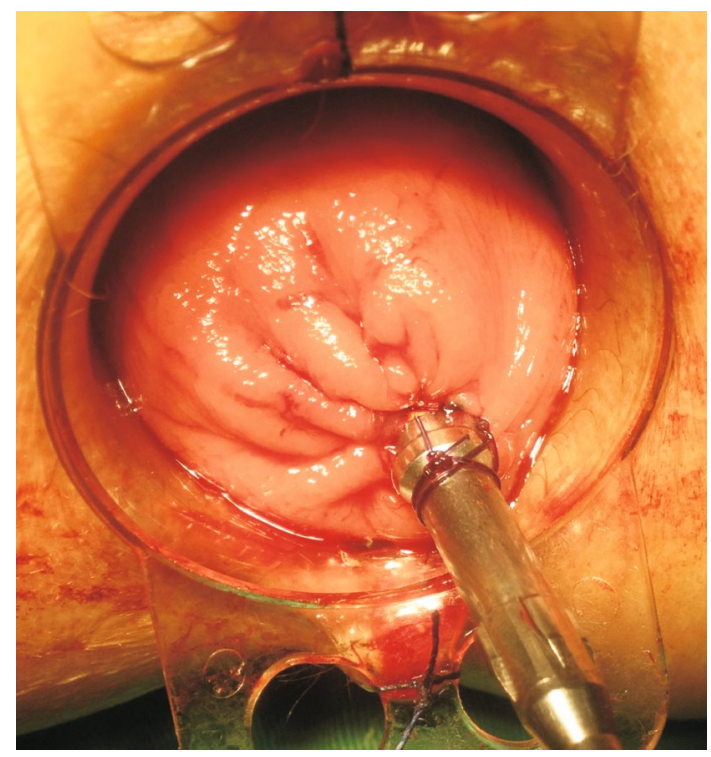

Fig. 3 Apex procedure after application of the second purse-string $1 \mathrm{~cm}$ distal to the first 
did not report on anatomical recurrence, they show a reduction in the mean Wexner score from 17 to 5 and a $6 \%$ recurrence of ODS symptoms at 12 months.

The circumferential removal of the prolapsed tissue using the Contour Transtar stapler is also an efficient technique because it is possible to quantify the amount of tissue to remove and the stapled suture can be positioned close to the dentate line, consequently treating both rectal intussusception and the rectocele [8]. However, its main limitation is the high cost (six cartridges are required) and the operative time is longer.

Finally, Naldini and colleagues make a comparison between the amount of tissue removed with the TST STARR PLUS, the PPH03 and the Transtar. The median height of the surgical specimen of $5.6 \mathrm{~cm}$ (range $4.5-10 \mathrm{~cm}$ ) and the surface area removed (average $45 \mathrm{~cm}^{2}$ ) by the TST STARR PLUS compare favorably with that of two firings of the PPH (average $37 \mathrm{~cm}^{2}$ ) or the multiple firings of the Transtar (average $54 \mathrm{~cm}^{2}$ ). The median height of the tissue removed using the EEA 33 is $5.9 \mathrm{~cm}$ (range $5-7.5 \mathrm{~cm}$ ) which is comparable to that removed with the TST STARR PLUS [4].

In conclusion, new dedicated staplers are now available to resect rectocele and internal rectal prolapse transanally. Their common characteristics are the capacity to remove large amounts of tissue, the ability to monitor the amount of tissue incorporated and improved hemostasis. Together with more stringent selection criteria and improved knowledge of multicompartmental prolapse, this represents a progress in the treatment of the anatomical defects associated with ODS.

\section{Compliance with ethical standards}

Conflict of interest The authors declare that they have no conflict of interest.
Ethical approval This article does not contain any studies with human participants or animals performed by any of the authors.

Informed consent For this type of study formal consent is not required.

\section{References}

1. Pescatori M, Favetta U, Dedola S, Orsini S (1997) Stapled transanal excision of rectal mucosal prolapse. Tech Coloproctol 1:96-98

2. Naldini G, Fabiani B, Menconi C et al (2017) Treatment of obstructed defecation syndrome due to rectocele and rectal intussusception with a high volume stapler. Tech Coloproctol. https:// doi.org/10.1007/s10151-017-1696-7

3. Pescatori M, Spyrou M, Pulvirenti d'Urso A (2007) A prospective evaluation of occult disorders in obstructed defecation using the 'iceberg diagram'. Colorectal Dis 9(5):452-456

4. Regadas FSP, Murad-Regadas SM, Wexner SD et al (2007) Anorectal three-dimensional endosonography and anal manometry in assessing anterior rectocele in women: a new pathogenesis concept and the basic surgical principle. Colorectal Dis 9:80-85

5. Regadas FSP, Regadas SMM, Rodrigues LV, Misici R, Silva FR, Regadas Filho FS (2005) Transanal repair of rectocele and full rectal mucosectomy with one circular stapler: a novel surgical technique. Tech Coloproctol 9:63-66

6. Nahas SC, Borba MR, Brochado MC, Marques CFS, Nahas CSR, Miotto-Neto B (2003) Stapled hemorrhoidectomy for the treatment of hemorrhoids. Arq Gastroenterol 40(1):35-39

7. Regadas FSP, Abedrapo M, Cruz JV, Regadas SMM, Regadas FSP (2014) Apex technique in the treatment of obstructed defecation syndrome associated with rectal intussusception and full rectal mucosa prolapse. Dis Colon Rectum 57:1324-1328

8. Lenisa L, Schwandner O, Stuto A et al (2009) STARR with Contour $^{\circledR}$ Transtar $^{\mathrm{TM}}$ : prospective multicenter European study. Colorectal Dis 11(8):821-827 